\title{
MANAGEMENT OF THE PATIENT WITH ADVANCED AMYOTROPHIC LATERAL SCLEROSIS: THE CAREGIVER'S OPINION
}

\author{
Maria Rivara ${ }^{1}$, Cornelius Barlascini ${ }^{2}$, Paolo Banfi ${ }^{3}$, Antonello Nicolini ${ }^{1}$, Bruna Grecchi ${ }^{4}$ \\ ${ }^{1}$ Respiratory Diseases Unit and ALS Centre, Hospital of Sestri Levante, Italy \\ ${ }^{2}$ Hygiene and Health Medicine Unit, Hospital of Sestri Levante, Italy \\ ${ }^{3}$ Don Gnocchi Foundation and Neuromuscular Diseases Centre, IRCSS, Milan \\ ${ }^{4}$ Physical Medicine and Rehabilitation Unit, ASL 4 Chiavarese, Italy
}

\begin{abstract}
Objectives. The possibility of prolonging and augmenting the quality of life of respiratory patients in end-stage disease and in particular neuromuscular disease patients depends on an increased level of care. Amyotrophic lateral sclerosis (ALS) is a neurological disease characterized by a fast progressive impairment of respiratory function which leads to mechanical ventilation and high burden of care. A specifically designed questionnaire was administered to caregivers to analyze the level of care provided to these patients in our districts.

Patients and methods. The study population consisted of 70 patients (44 males and 26 females). Of the 70 patients, 46 were being treated with non-invasive ventilation and 24 with invasive mechanical ventilation. The questionnaire was divided in two parts: questions 1 to 13 investigated life conditions and 14 to 22 the quality of care provided.

Results. The patients studied present a heavy burden of care and this is in relation to the quantity of respiratory aids prescribed. The symptom which created statistically significant problems for care was breathlessness, as is often reported in the literature. The presence of homecare tended to create conditions of greater serenity for the caregivers.

Conclusions. This study shows that the burden of care in end-stage ALS patients is very onerous, and it can help to point out problems not sufficiently contemplated in healthcare planning.
\end{abstract}

Keywords: amyotrophic lateral sclerosis, chronic respiratory failure, caregiver, burden of care

\section{INTRODUCTION}

Amyotrophic lateral sclerosis (ALS) is a neurological disorder characterized by a progressive impairment of motoneuron function due to degeneration of upper and lower motor neurons (1).

The improvement of medical care techniques is increasing the number of end-stage respiratory patients dependent on the continuous administration of mechanical ventilation and mechanical cough assistor. This situation is contrasted with a modified social and family organization which is not always ready and prepared to sustain this burden of care $(1,2)$. Symptoms of depression, lifestyle changes and a reduction in working hours are constant find- ings among caregivers of family members with severe respiratory problems $(2,3)$. The literature also reports of the significant economic burden and provision of care which the family must sustain in a chronic setting such as the end-stage respiratory patient (2-4). In addition, the increasing need for care and surveillance of these patients is also well known (2-5). This has prompted numerous studies which have evaluated either the psychosocial condition of the caregivers $(2,3,4)$ or the quality of care seen from the perspective of the patient $(5,6)$.

The aim of our study is the evaluation of:

- the perception of the caregiver in terms of the state of health of their loved one; 
- their perception of the degree and quality of care provided;

- the socio-economic situation of the caregiver of patients affected by a severe and

- progressive respiratory condition subject to home mechanical ventilation.

\section{MATERIALS AND METHODS}

We enrolled 96 caregivers of patients affected by end-stage respiratory failure due to ALS. Eightyone of them accepted to participate to the study, fifteen refused.

A specially designed questionnaire was administered to each caregiver. The questionnaire was proposed directly to the caregiver during a routine check-up of the patient. The aims of the study were clearly illustrated by a healthcare worker who was not involved in the care of the patient and the material was returned anonymously to a non-healthcare worker at each centre. The results of the questionnaire were processed independently by an operator external to the study.

The questionnaire has been reproduced in Appendix 1 and can be divided into two main parts. Questions 1 to 13 investigate the life conditions of the patient and caregiver, while questions 14 to 22 seek the views of the caregiver in terms of the care received from the national healthcare system and from the physician who discharged the patient.

The first part of the questionnaire is further divided into two sub-groups. The first analyses the lifestyle changes the caregiver had made (e.g. possible changes in the type of work, economic problems and the possible support received from other persons such as family or friends). The second subgroup of questions investigates the impact and psychological burden derived from caring for a person with a progressive and invalidating disease. The second part of the questionnaire, which as stated sought the perception of the quality of care received, was aimed at quantifying the relative level of satisfaction with the care provided by the centre where the patient was treated, from the home nursing service and lastly from the patient's general practitioner, with particular reference to possible problems regarding the use of respiratory support systems at home and the real availability of the various healthcare workers. The questionnaire was drawn up by a group of pulmonologists, physiotherapists and nurses operating in both centers. The questions of the questionnaire were processed and agreed upon by the physicians, physiotherapists and nurses involved in the study.

\section{Ethical consideration}

The study was conducted after obtaining the confirmation of Local Ethics Committees. Every subject involved in the study has given the informed consent.

\section{Statistical analysis}

A descriptive analysis of the case series was performed with the Snedcor-Fisher F-test to evaluate the statistical differences between the group of patients with a greater number of prescribed respiratory aids (invasive mechanical ventilation group A) and the group of patients with lesser aids prescribed (non invasive ventilation group B) as well as a non parametric stratified analysis with the Pearson chisquared test. The two groups were compared to investigate the difference of factors associated with burn-out of the caregiver (Table 2), difficulty of the caregiver (Table 3 ) or factors possibly involved in producing or upsetting the serenity of the caregiver (Table 4). Findings were considered significant for $p<0.05$.

\section{RESULTS}

Seventy caregivers fully responded to the questionnaire (86.4\% of interviewees). The responses showed that in most cases patients are cared for by a close relative (usually the partner). Caregivers had to frequently modify their work choices or lifestyle as well as suffer the burden of increased expenses due mainly to the cost of transporting the patient. The responses also revealed that the care provided to the patient, both by the various healthcare facilities and the patient's general practitioner, was considered satisfactory for nearly all of the respondents.

Tables 1-4 summarize the main findings. The two groups were not different in influencing the sense of burnout, of excessive burden of care, or in contrast in creating conditions of serenity for the caregiver (Table 1).

Table 2 shows that none of the factors associated with burn-out of the caregiver reached statistical significance. Burn-out was present in more than a third of the respondents, although this does not seem to be influenced by the patient's symptoms, the burden of care or the care provided by the healthcare services. In contrast some factors are significantly present, thus dividing the caregivers into those with or without difficulty in providing care (Table 3). When present, breathlessness proved to be a management problem in the group of care- 
TABLE 1. Description of cases

\begin{tabular}{|l|c|c|c|c|c|}
\hline \multirow{2}{*}{} & \multicolumn{2}{|c|}{$\begin{array}{c}\text { NIV 46 pts } \\
\text { (65.7\%) }\end{array}$} & \multicolumn{2}{c|}{$\begin{array}{c}\text { IMV 24 pts } \\
\mathbf{( 3 4 . 3 \% )}\end{array}$} & $\begin{array}{c}\text { P } \\
\text { value* }\end{array}$ \\
\cline { 2 - 7 } & $\mathrm{n}$ & $\%$ & $\mathrm{n}$ & $\%$ & \\
\hline Women & 19 & 41.3 & 7 & 29.1 & 0.07 \\
\hline Men & 27 & 58.7 & 17 & 70.9 & 0.09 \\
\hline Duration MV 3 years or less & 22 & 47.8 & 11 & 45.8 & 0.77 \\
\hline More than 3 years & 24 & 52.2 & 13 & 54.2 & 0.82 \\
\hline $\begin{array}{l}\text { Hospitalized at least once } \\
\text { in last 3 months }\end{array}$ & 11 & 23.9 & 5 & 20.8 & 0.68 \\
\hline $\begin{array}{l}\text { Caregiver reports } \\
\text { "burn-out" }\end{array}$ & 10 & 21.7 & 11 & 45.8 & 0.03 \\
\hline $\begin{array}{l}\text { Caregiver reports } \\
\text { "difficulty" }\end{array}$ & 12 & 26.1 & 14 & 58.3 & 0.04 \\
\hline $\begin{array}{l}\text { Caregiver reports sense of } \\
\text { "serenity" }\end{array}$ & 8 & 17.3 & 6 & 25.0 & 0.14 \\
\hline
\end{tabular}

*Snedcor-Fisher F-test

MV - mechanical ventilation

NIV - noninvasive mechanical ventilation

IMV - invasive mechanical ventilation

givers with difficulty, whereas the presence of homecare was more commonly associated with caregivers who perceived no difficulties in providing care.

Table 4 shows that the presence of a greater burden of care is significantly present in the caregivers with difficulties in relation to which external factors such as medical care or the support of other people, do not seem to help.

TABLE 2. Factors associated with caregiver's burn-out

\begin{tabular}{|c|c|c|c|c|c|c|}
\hline \multicolumn{7}{|c|}{ SENSE of "BURNOUT" } \\
\hline & & \multicolumn{2}{|c|}{ Yes } & \multicolumn{2}{|c|}{ No } & \multirow{2}{*}{$\begin{array}{c}\text { p } \\
\text { value* }\end{array}$} \\
\hline & $\mathrm{N}$. & $\mathrm{n}$ & $\%$ & $\mathrm{n}$ & $\%$ & \\
\hline $\begin{array}{l}\text { Support from other persons } \\
\text { present (Q. 2) }\end{array}$ & 68 & 9 & 36.0 & 25 & 55.6 & 0.14 \\
\hline $\begin{array}{l}\text { Availability of healthcare } \\
\text { benefits }\end{array}$ & 43 & 7 & 43.8 & 6 & 22.2 & 0.18 \\
\hline $\begin{array}{l}\text { Excessive economic burden } \\
\text { for the care }\end{array}$ & 55 & 2 & 14.3 & 9 & 22.0 & 0.71 \\
\hline $\begin{array}{l}\text { Support of friends, relatives, } \\
\text { religious or other present }\end{array}$ & 66 & 13 & 52.0 & 29 & 64.4 & 0.32 \\
\hline $\begin{array}{l}\text { Breathlessness frequent } \\
\text { symptom (Q. 9a) }\end{array}$ & 70 & 19 & 76.0 & 32 & 71.1 & 0.78 \\
\hline Anxiety or depression & 70 & 10 & 40.0 & 18 & 40.0 & 1.00 \\
\hline $\begin{array}{l}\text { Index of healthcare burden } \\
\text { relevant }\end{array}$ & 68 & 9 & 36.0 & 11 & 24.4 & 0.41 \\
\hline $\begin{array}{l}\text { Respiratory disease centre } \\
\text { assistance judged excellent } \\
\text { (Q. 17a) }\end{array}$ & 69 & 19 & 76.0 & 37 & 84.1 & 0.52 \\
\hline $\begin{array}{l}\text { Integrated homecare } \\
\text { service proposed and } \\
\text { activated (Q. 18) }\end{array}$ & 64 & 12 & 57.1 & 19 & 44.2 & 0.43 \\
\hline $\begin{array}{l}\text { Local healthcare centre } \\
\text { homecare programme } \\
\text { satisfactory (Q. 19) }\end{array}$ & 30 & 3 & 27.3 & 7 & 36.8 & 0.70 \\
\hline $\begin{array}{l}\text { Support provided by nurses } \\
\text { judged satisfactory (Q. 20) }\end{array}$ & 30 & 5 & 50.0 & 13 & 65.0 & 0.46 \\
\hline
\end{tabular}

$\mathrm{Q}=$ question
TABLE 3. Factors associated with caregiver's difficulty

\begin{tabular}{|c|c|c|c|c|c|c|}
\hline \multicolumn{7}{|c|}{ SENSE of DIFFICULTY } \\
\hline & \multirow{2}{*}{ N. } & \multicolumn{2}{|c|}{ Yes } & \multicolumn{2}{|c|}{ No } & \multirow{2}{*}{$\begin{array}{c}\mathbf{p} \\
\text { value* }\end{array}$} \\
\hline & & $\mathrm{n}$ & $\%$ & $\mathrm{n}$ & $\%$ & \\
\hline $\begin{array}{l}\text { Support from other persons } \\
\text { present (Q. 2) }\end{array}$ & 68 & 22 & 47.8 & 24 & 52.2 & 1.00 \\
\hline $\begin{array}{l}\text { Availability of healthcare } \\
\text { benefits }\end{array}$ & 43 & 8 & 33.3 & 5 & 26.3 & 0.74 \\
\hline $\begin{array}{l}\text { Excessive economic burden } \\
\text { for the care }\end{array}$ & 55 & 9 & 27.3 & 2 & 9.1 & 0.17 \\
\hline $\begin{array}{l}\text { Support of friends, } \\
\text { relatives, religious or other } \\
\text { present }\end{array}$ & 66 & 28 & 60.9 & 14 & 58.3 & 1.00 \\
\hline $\begin{array}{l}\text { Breathlessness frequent } \\
\text { symptom (Q. 9a) }\end{array}$ & 70 & 39 & 84.8 & 12 & 50.0 & 0.00 \\
\hline Anxiety or depression & 70 & 21 & 45.7 & 7 & 29.2 & 0.21 \\
\hline $\begin{array}{l}\text { Index of healthcare burden } \\
\text { relevant }\end{array}$ & 68 & 14 & 30.4 & 6 & 25.0 & 0.78 \\
\hline $\begin{array}{l}\text { Respiratory disease centre } \\
\text { assistance judged excellent } \\
\text { (Q. 17a) }\end{array}$ & 69 & 39 & 84.8 & 17 & 73.9 & 0.33 \\
\hline $\begin{array}{l}\text { Integrated homecare } \\
\text { service proposed and } \\
\text { activated (Q. 18) }\end{array}$ & 64 & 15 & 36.6 & 16 & 69.6 & 0.02 \\
\hline $\begin{array}{l}\text { Local healthcare centre } \\
\text { homecare programme } \\
\text { satisfactory (Q. 19) }\end{array}$ & 30 & 3 & 20.0 & 7 & 46.7 & 0.25 \\
\hline $\begin{array}{l}\text { Support provided by nurses } \\
\text { judged satisfactory (Q. 20) }\end{array}$ & 30 & 7 & 46.7 & 11 & 73.3 & 0.26 \\
\hline
\end{tabular}

$Q=$ question

TABLE 4. Factors associated with caregiver's serenity

\begin{tabular}{|c|c|c|c|c|c|c|}
\hline \multicolumn{7}{|c|}{ SENSE of SERENITY } \\
\hline & \multirow{2}{*}{$\mathbf{N}$. } & \multicolumn{2}{|c|}{ Yes } & \multicolumn{2}{|c|}{ No } & \multirow{2}{*}{$\begin{array}{c}p \\
\text { value* }\end{array}$} \\
\hline & & $\mathrm{n}$ & $\%$ & $\mathrm{n}$ & $\%$ & \\
\hline $\begin{array}{l}\text { Support from other persons } \\
\text { present (Q. 2) }\end{array}$ & 68 & 6 & 50.0 & 28 & 48.3 & 1.00 \\
\hline $\begin{array}{l}\text { Availability of healthcare } \\
\text { benefits }\end{array}$ & 43 & 2 & 20.0 & 11 & 33.3 & 0.70 \\
\hline $\begin{array}{l}\text { Excessive economic burden } \\
\text { for the care }\end{array}$ & 55 & 1 & 8.3 & 10 & 23.3 & 0.42 \\
\hline $\begin{array}{l}\text { Support of friends, } \\
\text { relatives, religious or other } \\
\text { present }\end{array}$ & 66 & 7 & 58.3 & 35 & 60.3 & 1.00 \\
\hline $\begin{array}{l}\text { Breathlessness frequent } \\
\text { symptom (Q. 9a) }\end{array}$ & 70 & 6 & 50.0 & 45 & 77.6 & 0.07 \\
\hline Anxiety or depression & 70 & 3 & 25.0 & 25 & 43.1 & 34.0 \\
\hline $\begin{array}{l}\text { Index of healthcare burden } \\
\text { relevant }\end{array}$ & 68 & 0 & 0.0 & 20 & 34.0 & 0.01 \\
\hline $\begin{array}{l}\text { Respiratory disease centre } \\
\text { assistance judged excellent } \\
\text { (Q. 17a) }\end{array}$ & 69 & 11 & 91.7 & 45 & 78.9 & 0.44 \\
\hline $\begin{array}{l}\text { Integrated homecare } \\
\text { service proposed and } \\
\text { activated (Q. 18) }\end{array}$ & 64 & 8 & 66.7 & 23 & 44.2 & 0.21 \\
\hline $\begin{array}{l}\text { Local healthcare centre } \\
\text { homecare programme } \\
\text { satisfactory (Q. 19) }\end{array}$ & 30 & 4 & 57.1 & 6 & 26.1 & 0.18 \\
\hline $\begin{array}{l}\text { Support provided by nurses } \\
\text { judged satisfactory (Q. 20) }\end{array}$ & 30 & 7 & 87.5 & 11 & 50.0 & 0.10 \\
\hline
\end{tabular}

$Q=$ question 


\section{DISCUSSION}

Respiratory failure is the most common cause of death for individuals with ALS, but the lives of most of these patients can be significantly prolonged by support $(6,7)$. The introduction of mechanical ventilation (both non-invasive and invasive) increased the burden of care for patients with neuromuscular diseases (7-9).

Our study shows that the burden of care for severe respiratory ALS patients is extremely onerous, with a significant impact for the caregiver. These findings confirm other studies which have emphasized that the main problems encountered by caregivers are lifestyle changes, reduction in work activity and onset of symptoms of depression $(2,3,4)$, with a degree of severity comparable to that experienced by caregivers of patients with Alzheimer's disease (4). It is also known that the quality of life of patients with respiratory symptoms is worse than in patients suffering from chronic heart failure or lung cancer (4). In addition, it should be noted that patients with respiratory complications usually receive less homecare and palliative treatment than patients with lung cancer $(10,11)$. Despite the full participation of the caregivers in filling out the questionnaire, this study has a number of limitations.

The study was conducted in only two respiratory centers of North Italy and therefore it provided a limited picture of the ALS situation.
Another limitation is the fact that the clinicians who participated in the study dedicate most of their activity to the care of chronic respiratory patients and this could in some way produce a more positive result than in other less dedicated respiratory settings. In previous studies non-Italian authors have attempted to describe the level of care of patients with advanced chronic respiratory failure (12), but only in rare cases have attempts been made to evaluate the impact of the disease on their life conditions $(2,3)$.

\section{CONCLUSIONS}

This study shows that the burden of care in severe respiratory patients as ALS patients is very onerous, with a significant impact for the caregiver. It may contribute to highlight a problem which is still not sufficiently recognized by the general public and healthcare planners not only in our country but worldwide by providing suggestions for the formulation of increasingly effective healthcare responses.

\section{Acknowledgments}

We thankfully acknowledge dr. Nicola R. Pizio and dr. Fabrizio Gallo for the valuable cooperation in this study.

\section{APPENDIX 1: THE QUESTIONNAIRE}

\section{PART 1. PATIENT CONDITIONS}

1. Who is the main caregiver?

a. Family member

b. Family members + integrated homecare

c. Paid caregiver

d. Other (voluntary ................)

2. Are you supported by other persons (friends, relatives) in caring for your family member?

a. Yes

b. No

3a. Have you had to change your work choices to care for your relative?

a. Yes

b. No

3b. If you were able to have more time off from work, would you accept to provide additional care to your relative?

a. Yes

b. No

4. Does the current situation involve additional expenses?

a. Yes

b. No
5. If Yes, why?

a. Equipment (bed, wheelchair)

b. Material for ventilation or tracheostomy

c. Visits to specialists

d. Home nursing

e. Medication

f. Paid homecare

g. Transport

6. Do you have serious economic problems in sustaining this situation?

a. Yes

b. No

7. How would you describe your current frame of mind in caring for your relative?
a. Denial
b. Uncertainty
c. Insecurity
d. Anger
e. Resignation
f. Fatigue
g. Serenity
h. Difficulty 
8. Has the patient had support of some other kind during this period?

a. None

b. Religious

c. Friends

d. Voluntary association

e. Other.

9. What is the most frequent symptom the patient suffers?

a. Breathlessness

b. Chest pain

c. Increased secretions

d. Sleep disturbances

e. Headache

f. Mental confusion

g. Anxiety

h. Depression

i. Abdominal pain

j. Constipation

k. Other

10. Are you aware of a progressive worsening of the patient's disease?
a. Yes

b. No

11. Do you believe the patient is aware of the severity of the prognosis of his/her disease?
a. Yes
b. No
c. I do not know

12. If Yes, who explained the severity and the prognosis of the disease to the patient?
a. The general practitioner
b. The specialist
c. Other

13. Have you had difficulties using the prescribed respiratory support?
a. Yes
b. No

\section{PART 2. PERCEIVED QUALITY}

14. Has the patient been hospitalized in the last three months?

a. Yes

b. No

15. What was the reason for the hospitalization?

a. Respiratory problems

b. Heart problems

c. Nutritional problems

d. Other
16. Onto which ward was the patient admitted?
a. Intensive care
b. Respiratory
c. General medicine
d. Emergency
e. Other

17. How would you evaluate the assistance provided by the respiratory disease centre?
a. Unsatisfactory
b. Satisfactory
c. Good
d. Excellent

18. Has integrated homecare ever been proposed?

a. Yes

b. No

19. If Yes, how would you evaluate the program of homecare provided by your local healthcare centre?

a. It is a very satisfying service, even better than I expected

b. It is a quite satisfying service in line with my expectations

c. It is a relatively satisfying service

d. It is not a very satisfying service

e. It is a completely unsatisfying service, much worse than I expected

20. Are you satisfied with the support provided by the nurses?

a. Yes, I am completely satisfied

b. Yes, I am partially satisfied

c. I am neither satisfied nor unsatisfied

d. No, I am partially unsatisfied

e. No, I am totally unsatisfied

21. Were you unable to contact your general practitioner or nurse at any time?
a. Yes very often
b. Yes often
c. Yes occasionally
d. Rarely
e. No never

22. Are you satisfied with the support provided by your general practitioner in this period?

a. Yes, I am completely satisfied

b. Yes, I am partially satisfied

c. I am neither satisfied nor unsatisfied

d. No, I am partially unsatisfied

e. No, I am totally unsatisfied

\section{REFERENCES}

1. Miller R.G., Jackson C.E., Kararskis J.P., England J.P., Forshew D., Kalra S. et al. Practice parameter update. The care of patient with amyotrophic lateral sclerosis .Drug, nutritional, and respiratory therapies. Evidence based review. Neurology 2009; 73:1218-1226

2. Vitacca M.,Comini L., Barbano L. Home mechanical ventilation difficulties in the last three months of life reported by caregivers.

J Med Pers 2013; 11(1):30-36
3. Lillo P., Mioshi E., Hodges J.R. Caregiver burden in amyotrophic lateral sclerosis is more dependent on patients' behavioral changes than physical disability: a comparative study. BMC Neurol 2012; 12:156

4. Vitacca M., Grassi M., Barbano L., Galavotti G., Sturani C., Vianello A. et al. Last months of life in home-ventilated patients: the family perception. ERJ 2009; 35 (5):1064-1071 
5. Douglas S.L., Daly B.J. Caregivers of long-term ventilator patients. Chest 2005; 123:1073-81

6. Bach J.R. A Comparison of long-term ventilatory support alternatives from the perspective of the patient and caregiver Chest 1993; 104:1702-06

7. Bach J.R., Mehta A.D. Respiratory muscle aids to avert respiratory failure and tracheostomy: a new patient management paradigm J Neurorestoratol 2014; 2:25-35

8. Bach J.R. ALS prolongation of life by non invasive respiratory AIDS. Chest 2002; 122(1):92-8

9. Ishikawa Y. Manual for the care of the patients using non invasive ventilation. Matsudo, Japan-Japan Planning Center 2005
10. Gore J.M., Brophy C.J., Greenstone M.A. How well do we care for patients with end stage chronic obstructive pulmonary disease (COPD)? A comparison of palliative care and quality of life in COPD and lung cancer. Thorax 2000; 55:1000-1006

11. Claessens M.T., Lynn J., Zhong Z. Dying with lung cancer or chronic obstructive pulmonary disease: insights from SUPPORT, Study to Understand Prognoses and Preferences for Outcomes and Risks of Treatments. J Am Geriatr Soc 2000; 48:S146-S153

12. Ambrosino N., Goldstein R. Series of comprehensive management of end-age COPD. Eur Resp J 2007; 30:828-830 